\title{
Postural Effects on Normal Oropharyngeal Swallowing: Videofluoroscopic Swallow Study (VFSS)
}

\author{
Original Ahlam Abdel-Salam El-Adawy', Ahmed Mamdouh Imam², Rasha Hashem ${ }^{3}$,Eman \\ Article Mostafa ${ }^{4}$, \\ ${ }^{1,2,4}$ Otolaryngology Department, Phoniatric Unit, Faculty of Medicine, Sohag University, \\ ${ }^{3}$ Phoniatric Specialist in General Administration of Medical Affairs, Sohag University
}

\begin{abstract}
Background: There is considerable amount of research assessing the effect of posture (supine and upright) on swallowing. However, there are no previous studies that assess the difference between sitting and standing positions and their effect on swallowing.

Aim: To assess the physiological difference between standing and sitting positions in oropharyngeal phase of swallowing. Patients and Methods: Dynamic videofluoroscopic swallow studies were performed on 30 healthy adult volunteers (15 males and 15 females) ranging in age from 18 to 45 years. All volunteers were examined in sitting and standing positions with a lateral view using barium sulfate. Oral Transit Time and Pharyngeal Transit Time are measured. In addition, hyoid peak elevation is calculated.

Results: During studying fluid bolus, there was significant difference between sitting and standing positions in Pharyngeal Transit Time $(P$ value $=0.005)$. On the other hand, there was no significant difference between sitting $\&$ standing positions in Oral Transit Time.

Conclusion: Although the PTT was longer in the sitting position with a statistically significant difference with the standing position, it did not affect the hyoid peak elevation. Hence, the body position affected the duration of PTT without affecting the degree of displacement of the hyoid bone.
\end{abstract}

Key Words: Normal swallowing, posture, videofluoroscopy

Received: 29 December 2019, Accepted: 23 July 2020

Corresponding Author: Eman Mostafa, PhD, Assistant Professor of Phoniatrics, Department of Otolaryngology, Sohag University, Egypt. Tel.: 01003145617,E-mail: eman_mostafa@med.sohag.edu.eg

ISSN: 2090-0740, November 2020 Vol.21, No.3

\section{INTRODUCTION}

The videofluoroscopic swallowing study, a dynamic $\mathrm{x}$-ray examination, allows direct assessment of oral cavity, pharynx, and esophagus. Yet, radiation exposure limits the time of examination. Videofluoroscopy is considered the gold standard method for evaluation and diagnosis of dysphagia patients. Timing evaluation of the physiological events during swallowing relies exclusively on bony anatomic landmarks due to the limited visualization of soft tissues.

The measurement of swallow event timing has been shown to be clinically significant and is the first step toward establishing objective measures of swallow function ${ }^{[1,2]}$ Earlier, in the former studies, Normative data for many measures have not been established, however, and previously reported measures are often defined differently depending on the preferences of the reporting institution. ${ }^{[3,4,5]}$ For instances, the oral Transit time (TTO) has been defined in different ways; some studies define it as the interval between the complete capture of the bolus and the reflex firing of swallowing while others define it as the interval between the onset of the bolus propulsion until its initial portion exceeds the tongue baseline. ${ }^{[6]}$

Inagaki, Miyaoka, Ashida, Ueda, and Yamada ${ }^{[7]}$ examined nine normal young subjects at four different body positions: upright $\left(90^{\circ}\right), 60^{\circ}$ inclined, $30^{\circ}$ inclined, and horizontal supine $\left(0^{\circ}\right)$ body positions. The average duration of the oral phase after moving from the upright to the inclined and supine positions decreased. Also, Perry, $\mathrm{Bae}$, and $\mathrm{Kuehn}^{[8]}$ assessed the difference of the duration of the pharyngeal stage of swallowing in the upright versus the supine position. They reported that the difference was statistically significant between the two positions with longer pharyngeal times in the supine position than those in the upright position for male subjects. While females showed similar pharyngeal phase duration in both body positions, yet it was significantly longer than males. On the other hand, Johnsson, Shaw, Gabb, Dent, \& Cook $^{[9]}$ studied the difference between the reclining and sitting postures on pharyngeal Transit time and his results showed no significant difference between the two positions. 
Knowing that the duration of bolus pharyngeal transit is important as prolonged pharyngeal transit time may increase the risk of aspiration pneumonia in several patient populations. ${ }^{[1,3]}$ Kendall $^{[18]}$ noted that variations in the bolus size did not affect the bolus pharyngeal transit. Yet, Nascimento et al. ${ }^{[19]}$ mentioned that increase in the bolus consistency increased the duration of the bolus pharyngeal transit time. Posture (supine and upright) is another variable that urged many researchers to investigate its effect on swallowing. However, there are no previous studies that assessing the difference between sitting and standing positions and their effect on swallowing. To be noted, it is important to understand oro- pharyngeal swallowing physiology through studying different body positions.

Although sitting upright is the typical position for eating and drinking, the rapid rhythm of daily life activity encourages many people for eating and drinking in standing position. Moore ${ }^{[20]}$ and Tothill ${ }^{[21]}$ found that body posture and position placement of the externally located counting monitors influence radionuclide-based measurements of gastric emptying as standing position increase gastric emptying.

\section{Our research question is}

Does body position affect the duration of the oral Transit time (TTO), Pharyngeal Transit time (PTT) and the hyoid bone elevation peak?

\section{PATIENTS AND METHODS:}

Approval of the ethical committee was taken before the beginning of the research. Written consent was taken from all individual before the beginning of the study and after discussing the objectives of this study.

Dynamic videofluoroscopic swallow studies were performed on 30 healthy adult volunteers (15 males and 15 females) ranging in age from 18 to $45 \mathrm{yrs}$. None of our volunteers has history of dysphagia, gastroesophageal reflux disease (GERD) symptoms, neurological or musculoskeletal disorders, history of any oropharyngeal structural or functional abnormalities and history of radiotherapy.

The apparatus used for the procedure was videofluroscopy (PHILIPS type $9848 \quad 500 \quad 51001$ SN07001508 Duo Diagnost) which is a radiological equipment with image display connected to a DVD that allows recording for subsequent analysis, including use of slow motion for detailed investigation. The examination session consumed $6 \pm 2 \mathrm{~min}$. The VFSS took place in a standard radiology fluoroscopy suite. Dose rate during examination during continuous fluoroscopy mode is $(1.23 \mu \mathrm{Gy} / \mathrm{s})$. The fluoroscope was activated for a few seconds before and after the administration of the barium substances.
All volunteers were examined in both sitting and standing positions. They were asked to establish a comfortable head position making sure that the head is not tilted toward either shoulder nor flexed or extended. In both body positions the subject was examined in the lateral view. The visualization field included the lips anteriorly, nasal cavity superiorly, cervical spinal column posteriorly, and the entire pharyngoesophageal segment (PES) inferior. The larynx was in full view within this visualization field. The fluoroscope was deactivated shortly after the bolus tail had exited the cervical esophageal region.

\section{Boluses:}

Oral contrast agents were prepared using barium sulfate. The protocol included intake of two liquid boluses and two solid boluses. The number of boluses administrated during examination was four boluses. The liquid bolus consisted of $10 \mathrm{ml}$ (1:1 consistency) and solid bolus (cookies soaked in liquid barium). Swallowed liquid material was presented to the subject by cup.

\section{Swallow events and Timing measures:}

\section{Timing measures were reported in seconds.}

1- Oral Transit time (TTO): Is the duration measure of bolus movement through the oral cavity. The end of oral stage is determined as the moment when the head of the bolus passes the ramus of the mandible.

2- Pharyngeal Transit time (PTT): Frames were counted from the point where the swallow was triggered to the point where the bolus passed the cricopharyngeal segment. The point where the swallow was triggered was marked by the bolus head passing the ramus of the mandible. The end of the pharyngeal stage was determined by the passing of the entire bolus through the cricopharyngeal segment, which was determined as the segment of tissue at the same horizontal level of the vestibule or opening to the larynx. ${ }^{[10]}$

The videos of each swallow were reviewed by two experienced phoniaticians. Frame by frame images (30 frames per second) were obtained and analyzed.

\section{Calculation of hyoid peak elevation:}

Two frames obtained (the $1^{\text {st }}$ one at the onset of hyoid bursts $\&$ the $2^{\text {nd }}$ one at the end of hyoid bursts). The frames imported to Image $\mathrm{J}$ software, using a coordinate system with an origin at the anterior-inferior corner of the C4-vertebrae and vertical axis defined by a line running from the origin upwards through the anteriorinferior corner of the C2-vertebrae (see Fig 1). The distance between the anterior-inferior corners of the $\mathrm{C} 2$ and $\mathrm{C} 4$ vertebrae also served as an anatomical scalar to enable us to control for differences in the size of the pharynx across participants during measurements of hyoid 
movement distance. ${ }^{[11]}$ An algorithm in Excel spread sheet organized for calculation of hyoid peak position software was used to index the onset and end of the anterosuperior hyoid burst movement for each swallow.

The onset of the hyoid burst movement was defined as the lowest position before the start of hyoid movement and the peak hyoid position, calculated in both $\mathrm{X}$ and $\mathrm{Y}$ directions. The end of hyoid burst movement was defined as the peak of maximal hyoid position within the hyoid position history, calculated in both $\mathrm{X}$ and $\mathrm{Y}$ directions. This permitted the derivation of measures of maximum hyoid displacement (in anatomically normalized units, i.e., \% of the C2-4 vertebral distance), distance travelled (maximum displacement minus onset position, in \% C2-4 units).

\section{Statistical analysis:}

Statistical package for social Sciences version 16 (SPSS, INC, Chicago, IL) under windows was used

Table 1: Comparison between sitting and standing positions in the duration of all phases of swallowing during fluid bolus swallowing.

\begin{tabular}{ccccc}
\hline Variable & Mean \pm SD $($ sec. $)$ & T value & P value \\
\hline TTO & Sitting & $1.86 \pm 0.95$ & & \\
& Standing & $1.78 \pm 0.74$ & & \\
PTT & Sitting & $0.74 \pm 0.13$ & \\
& & & \\
& Standing & $0.66 \pm 0.14$ & $0.005^{*}$ \\
\hline \multicolumn{4}{c}{$*$ Significant difference }
\end{tabular}

During swallowing solid bolus, there was no significant difference between sitting and standing positions in the duration of all phases of swallowing (Table 2).

Table 2: Comparison between sitting and standing positions in the duration of all phases of swallowing during solid bolus swallowing.

\begin{tabular}{ccccc}
\hline & & & & \\
Variable & Mean $\pm \mathrm{SD}(\mathrm{sec})$. & T value & P value \\
\hline TTO & Sitting & $7.39 \pm 3.47$ & & \\
& & & & \\
& Standing & $7.81 \pm 3.35$ & & \\
PTT & Sitting & $0.58 \pm 0.13$ & & \\
& & & 1.01 & 0.32 \\
& Standing & $0.63 \pm 0.16$ & & \\
\hline
\end{tabular}

for data entry and analysis. Descriptive statistics were done for continuous variables by mean, standard deviation $( \pm \mathrm{SD})$. A paired t-test was performed to make comparisons between the upright and the supine position among subjects and between subject groups (males and females) for each measure obtained. A probability (p) value less than 0.05 was considered significant

\section{RESULTS:}

Thirty healthy volunteers (15 males \& 15 females) were recruited in the study, with mean age \pm SD (30.6 \pm 8.6). During studying fluid bolus, there was significant difference between sitting and standing positions in Pharyngeal Transit Time (PTT) with longer duration in the sitting position (mean $=0.74 \mathrm{sec}$ ) than the standing position $($ mean $=0.66 \mathrm{sec}, P$ value $=0$. 005) (Figure 2$)$. On the other hand, there was no significant difference between sitting \& standing positions in Oral Transit Time (TTO) (Table 1).

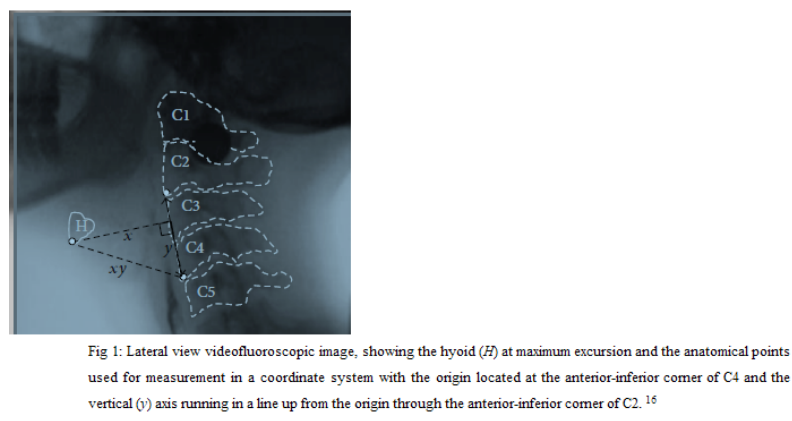

Fig. 1: Lateral view videofluoroscopic image, showing the hyoid $(\mathrm{H})$ at maximum excursion and the anatomical points used for measurement in a coordinate system with the origin located at the anterior-inferior corner of $\mathrm{C} 4$ and the vertical (y) axis running in a line up from the origin through the anterior-inferior corner of C2. ${ }^{[16]}$

During studying both the fluid bolus and the solid bolus, there were no significant differences between males and females in the duration of all phases of swallowing in both sitting and standing positions.

During swallowing fluid bolus, there was no significant difference between the sitting \& standing positions in both anterior \& superior hyoid peak elevation (Table 3). The same results were for the solid bolus (Table 4). 
Table 3: Hyoid peak elevation during fluid bolus swallowing in both sitting \&standing positions.

\begin{tabular}{|c|c|c|c|c|}
\hline Variable & Mean $\pm \mathrm{SD}$ & $\mathrm{T}$ value & & Pvalue \\
\hline \multirow[t]{2}{*}{ Superior hyoid peak elevation (\%) } & Sitting & $36.44 \pm 17.72$ & 0.817 & 0.421 \\
\hline & Standing & $38.91 \pm 15.90$ & & \\
\hline \multirow[t]{2}{*}{ Anterior hyoid peak elevation (\%) } & Sitting & $36.88 \pm 16.55$ & 0.227 & 0.823 \\
\hline & Standing & $38.21 \pm 15.66$ & & \\
\hline
\end{tabular}

Table (4): Hyoid peak elevation in both sitting \&standing positions during solid bolus swallowing.

\begin{tabular}{ccccc}
\hline Variable & Mean \pm SD & T value & P value \\
\hline Superior hyoid peak elevation (\%) & Sitting & $38.95 \pm 19.02$ & 1.717 & 0.097 \\
& Standing & $33.21 \pm 15.10$ & & 0.111 \\
Anterior hyoid peak elevation (\%) & Sitting & $36.59 \pm 15.71$ & & 0.913 \\
\hline
\end{tabular}

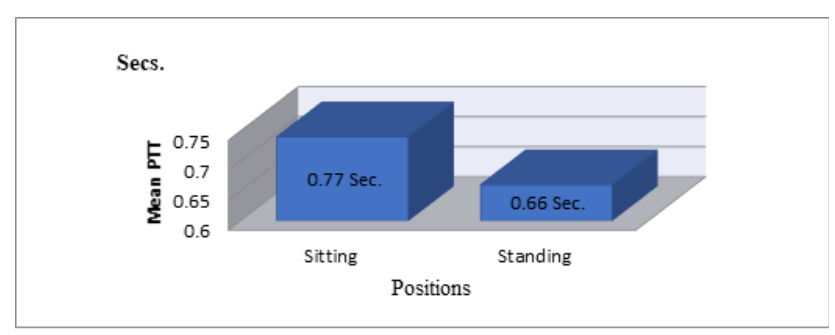

Figure (2): Difference between sitting and standing position during studying of PTT of

fluid bolus. PTT $=$ Pharyngeal Transient Time.

Fig. 2: Difference between sitting and standing position during studying of PTT of fluid bolus. PTT = Pharyngeal Transit Time.

\section{DISCUSSION}

During studying the fluid bolus, there was significant difference between sitting and standing positions in PTT with longer duration in the sitting position (mean $=0.74 \mathrm{sec}$ ) than the standing position ( mean $=0.66 \mathrm{sec}, P$ value $=0.005)$. Given the fact that signals from body position, swallowing and respiration are regulated in the brain stem especially the Nucleus tractus solitarius (NTS). Body position exerts its action through the baroreflex. ${ }^{[12]}$ Baroreceptor afferents terminate in the neurons of the NTS. ${ }^{[13]}$ Hence, it is plausible to note that the change in position may have been associated with change of the reflexive control of swallowing, shown by change of the duration of PTT.

Nitta, Iwasa, Sugita, Hirono, \& Shiba ${ }^{[14]}$ mentioned that signals from swallowing are connected with the respiration-induced signals, and the degree of fluctuation by respiration was modulated with body positions. The authors noticed that the fluctuations by respiration were the lowest level in standing compared to sitting and supine position. This indicated difference in the respiratory control during swallowing between sitting and standing positions. Further study is needed using VFSS combined with respiratory monitoring to assess the pattern of respiration during swallowing.

The longer duration of PTT in sitting position also may be due to later onset of hyoid movement \& this in turn leads to later onset of UES opening. As Dantas, Santos, Gonzaga, Alves, Mazin ${ }^{[15]}$ noted that a slower bolus was accompanied by later onset of that hyoid movement without significant differences in the maximal vertical and anterior displacement. As shown in (Table 3 and 4), there was no significant difference between the sitting \& standing positions in both anterior \& superior hyoid peak elevation during swallowing a $10 \mathrm{ml}$ fluid bolus or solid bolus.

In the current study, hyoid displacement during $10 \mathrm{ml}$ fluid swallowing in sitting position was $38.95(\mathrm{SD} \pm 19.02)$ superiorly \& 36.59 $(\mathrm{SD} \pm 15.71)$ anteriorly. In standing position the displacement was 33.21 ( $\mathrm{SD} \pm 15.10)$ superiorly \& 36.30 ( $\mathrm{SD} \pm 13.41)$ anteriorly. Thevaluesofhyoiddisplacement did not differ from the range that was mentioned by Nagy et al..$^{[16]}$ who examined the superior and anterior hyoid displacement (in \% C2-4 units) during swallowing $5 \mathrm{ml}, 10 \mathrm{ml} \mathrm{\&} 20 \mathrm{ml}$ liquid barium. The displacement was 33\% - 39\% anteriorly \& 39\% - 48\% superiorly, with no significant differences between varying consistencies.

Also in this study, there were no significant differences between males and females in the duration 
TTO and PTT in both sitting and standing positions. This is attributed to the absence of distinct swallowing patterns between genders as noted by Molfenter ${ }^{[17]}$. These results are not consistent with the results of Dantas et $a l .{ }^{[15]}$ who found significant differences between both genders. The authors explained this difference due to anatomical and physiological variations between men and women.

\section{Clinical implications:}

Our study demonstrated that PTT is affected by body position. These results may be useful in the assessment of disintegration time of oral tablets before they enter the esophagus and the stomach, knowing that assessment of disintegration is important in improving drug performance and absorption.

\section{CONCLUSION}

This Although the PTT was longer in the sitting position with a statistically significant difference with the standing position, it did not affect the hyoid peak elevation. Hence, the body position affected the duration of PTT without affecting the degree of displacement of the hyoid bone.

\section{CONFLICT OF INTEREST}

There are no conflicts of interest.

\section{REFERENCES}

1. Johnson, E. R., McKenzie, S. W., \& Sievers, A. (1993). Aspiration pneumonia in stroke. Arch Phys Med Rehabil, 74(9), 973-976.

2. Logemann JA, P. B., Rademaker A, Cook B, Graner D,, Milianti F, B. Q., Stein D, Bowman J, Lazaurus C, Heiser, \& MA, B. T. (1992). Impact of the diagnostic procedure on outcome measures of swallowing rehabilitation in head and neck cancer patients. , 1992. Dysphagia, 7, 179-186.

3. Bisch EM, Logemann J., Rademaker AW, Kahrilas PJ, Lazarus CL . ( 1994). Pharyngeal effects of bolus volume, viscosity, and temperature in patients with dysphagia resulting from neurologic impairment and in normal subjects. . J Speech Hear Res, 37:10411049, 1994, 1041-1049.

4. Curtis D, C. D., Dachman A, Maso E. (1984). Timing in the normal pharyngeal swallow. . Invest Radiol, 19, $523-529$

5. Stachler RJ, H. S., Mathog RH, Jones L, Heilbrun LK, Manov LJ, O’Campo JM. (1994). Swallowing of bolus types by postsurgical head and neck cancer patients. . Head Neck, 16, :413-419.

6. Soares, T. J., Moraes, D. P., de Medeiros, G. C., Sassi, F. C., Zilberstein, B., \& de Andrade, C. R. F. (2015). Oral Transit Time: A Critical Review of the Literature. Abcd-Arquivos Brasileiros De Cirurgia DigestivaBrazilian Archives of Digestive Surgery, 28(2), 144 147. doi: 10.1590/S0102-67202015000200015.

7. Inagaki, D., Miyaoka, Y., Ashida, I., Ueda, K., \& Yamada, Y. (2007). Influences of body posture on duration of oral swallowing in normal young adults. J Oral Rehabil, 34(6), 414-421. doi: 10.1111/j.13652842.2007.01737.x.

8. Perry, J. L., Bae, Y., \& Kuehn, D. P. (2012). Effect of posture on deglutitive biomechanics in healthy individuals. Dysphagia, 27(1), 70-80. doi: 10.1007/ s00455-011-9340-6.

9. Johnsson, F., Shaw, D., Gabb, M., Dent, J., \& Cook, I. (1995). INFLUENCE OF GRAVITY AND BODY POSITION ON NORMAL OROPHARYNGEAL SWALLOWING. American Journal of PhysiologyGastrointestinal and Liver Physiology, 269(5), G653-G658.

10. Murray, J. (1999). Manual of dysphagia assessment in adults. 1st edn. San Diego: Singular Publishing.

11. Molfenter, S. M., \& Steele, C. M. (2014). Use of an anatomical scalar to control for sex-based size differences in measures of hyoid excursion during swallowing. Journal of Speech, Language, and Hearing Research, 57(3), 768-778.

12. Mukai, S. \& Hayano, J. (1995) Heart rate and blood pressure variabilities during graded head-up tilt. Journal of Applied Physiology, 78, 212.

13. Cravo, S.L., Morrison, S.F. and Reis, D.J. (1991) Differentiation of two cardiovascular regions within the caudal ventrolateral medulla, Am. J. PhysioL ReguL Integr. Comp. Physiol., 261 R985-R994.

14. Nitta, E., Iwasa, Y., Sugita, M., Hirono, C., \& Shiba, Y. (2003). Role of mastication and swallowing in the control of autonomic nervous activity for heart rate in different postures. J Oral Rehabil, 30(12), 1209-1215.

15. Dantas RO, C. R., Santos CM, Gonzaga GC, Alves LMT, Mazin SC. . (2009). Effect of Gender on Swallow Event Duration Assessed by Videofluoroscopy. Dysphagia, 24, 280-284. 
16. Nagy, A., Molfenter, S. M., Péladeau-Pigeon, M., Stokely, S., \& Steele, C. M. (2014). The effect of bolus volume on hyoid kinematics in healthy swallowing. Dysphagia, 30(4), 445-451.

17. Molfenter SM, S. C. (2013). Variations in temporal measures of swallowing: sex and volume effects. Dysphagia. , 28(2), 226-233.

18. Kendall, KA, McKenzie, S, Leonard, RJ, Gonc, alves, MI, and Walker, A. (2000). Timing of Events in Normal Swallowing: A Videofluoroscopic Study. Dysphagia 15:74-83.
19. Nascimento, WV, Cassiani, RA, Santos, CM, and Dantas, RO (2015). Effect of Bolus Volume and Consistency on Swallowing Events Duration in Healthy Subjects. J Neurogastroenterol Motil. 21(1): 78-82. doi: 10.5056/jnm14055.

20. Moore, JG, Datz, FL, Christian, PE, Greenberg, E, and Alazaki N. (1980). Effect of Body Posture on Radionuclide Measurements of Gastric Emptying. Digestive Diseases and Sciences, 33 (12), 1592-1595.

21. Tothill P, McLoughlin GP, Holt S, Heading RC: The effect of posture on errors in gastric emptying measurements. Phys Med Biol 25(6):1071-1077, 1980. 